\title{
Efficacy of three methods for inserting calcium hydroxide-based paste in root canals
}

\author{
Thales Galvão ${ }^{1}$, Bernardo Camargo ${ }^{1}$, Luciana Armada ${ }^{2}$, Flávio Alves ${ }^{2}$ \\ ${ }^{1}$ MSc, Department of Endodontics, Faculty of Dentistry, Estácio de Sá University, Rio de Janeiro, RJ, Brazil \\ ${ }^{2} \mathrm{PhD}$, Department of Endodontics, Faculty of Dentistry, Estácio de Sá University, Rio de Janeiro, RJ, Brazil
}

Correspondence:

Faculty of Dentistry, Estácio de Sá University

Av. Alfredo Baltazar da Silveira, 580/cobertura

Recreio dos Bandeirantes

Rio de Janeiro, $R J$

Brazil 22790-710

luadias@hotmail.com

Galvão T, Camargo B, Armada L, Alves F. Efficacy of three methods for inserting calcium hydroxide-based paste in root canals. J Clin Exp Dent. 2017;9(6):e762-6.

http://www.medicinaoral.com/odo/volumenes/v9i6/jcedv9i6p762.pdf

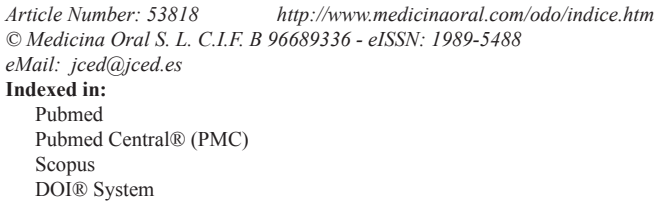

\begin{abstract}
Background: To compare the quality of calcium hydroxide paste fillings performed by three different techniques. Material and Methods: Sixty extracted maxillary central incisors, with previous root canal treatment, were decoronated and the gutta-percha was completely removed from the root canals. Subsequently, the canals were filled with a calcium hydroxide-based paste composed of calcium hydroxide, bismuth carbonate, and glycerin. The study samples were divided into the following three groups on the basis of three insertion techniques $(\mathrm{n}=20$, each): conventional technique using a hand instrument (MAN), rotary Lentulo spiral (LEN) technique, and a combined technique combining conventional hand files with sonic activation through the EndoActivator device (EA). The quality of fillings was evaluated radiographically by two examiners on the basis of the amount of voids and the apical limit.

Results: The canals filled with LEN or MAN had less void volume compared to the EA technique $(p<0.01)$, with no significant differences between them. Considering the apical limits, the three tested techniques showed comparable results $(p>0.05)$.

Conclusions: A combined approach utilizing hand files with sonic activation showed no enhancements over the LEN or MAN techniques on the quality of intracanal placement of calcium hydroxide paste.
\end{abstract}

Key words: Calcium hydroxide placement, EndoActivator, Lentulo spirals, intracanal medication, root canal treatment.

\section{Introduction}

Intracanal medication with calcium hydroxide $\left(\mathrm{Ca}(\mathrm{OH})_{2}\right)$ pastes is commonly used to complement the root canal disinfection after chemo mechanical preparation (1).
Studies have shown that this procedural step positively influences the outcomes of endodontic treatment in infected cases (1-3). However, a homogeneous filling up to working length (WL) is essential to ensure adequate 
effectiveness of $\mathrm{Ca}(\mathrm{OH})_{2}$ pastes (4). Several methods are used to deliver $\mathrm{Ca}(\mathrm{OH})_{2}$ pastes into the root canal, including a hand file, Lentulo spiral, and special devices such as syringes and compactors (5-7).

Studies comparing different techniques to fill root canals with $\mathrm{Ca}(\mathrm{OH})_{2}$ show controversial results. One study found that the endodontic hand file is superior to McSpadden compactor and Lentulo spiral in root canals of dogs premolars, and the endodontic hand file produced the lowest number of empty spaces in the three thirds evaluated (5). However, another study reported that there were no differences in outcomes between using a Lentulo spiral or a hand file in human mandibular premolars (8).

Alternative devices/techniques have been examined to improve the quality of $\mathrm{Ca}(\mathrm{OH})_{2}$ filling. For instance, one study compared different devices/instruments including $\mathrm{K}$-file, ultrasonic file, and Lentulo spiral in single-rooted premolars, and showed comparable quality of fillings (6). Currently, ultrasound as well as sonic devices are very popular among endodontists, and their applications include activation of irrigation solutions (9) and sealer placement (10). Sonic systems are suggested to improve the quality of $\mathrm{Ca}(\mathrm{OH})_{2}$ root canal filling; however, there is no scientific evidence that supports this statement, to date (11).

The aim of this study was to compare the quality of $\mathrm{Ca}(\mathrm{OH})_{2}$ paste filling performed by the following three different methods of application: conventional filling using a hand instrument, filling using a rotary Lentulo spiral, and conventional hand filling complemented by sonic activation. The research hypotheses were: (1) EndoActivator significantly improves the quality of paste filling; and (2) There is no significant difference between the tested techniques.

\section{Material and Methods}

-Teeth selection and initial preparation

Sixty human maxillary central incisors were obtained from a collection of the tooth bank of the University. Reasons for extraction were not related to this study and the research protocol was approved by the institutional ethics committee (CAAE: 0133.0.308.000.10). Teeth were canal-treated by undergraduate students, as part of their pre-clinical training in endodontics.

In all teeth, the filling material was mechanically removed by an LA Axxess \#45 (Sybron Dental Specialties Inc., Orange, CA, USA) in the coronal two-thirds and by hand files until a $50 \mathrm{~K}$-file (Maillefer Instruments SA, Ballaigues, Switzerland) $1 \mathrm{~mm}$ beyond of the apical foramen. The removal of filling was completed using Hedström files (Maillefer Instruments SA, Ballaigues, Switzerland), in circumferential filing motion, without chemical solvents. The root canals were irrigated with distilled water after each instrument change. At the end of canal preparation, the root canals were dried using paper points. The crowns were then removed using a diamond disc and bucco-lingual and mesio-distal radiographs were obtained to confirm the complete gutta-percha removal.

The apical foramen of each tooth was sealed with a fast setting epoxy resin to create a closed-end system. The study samples were divided into three groups of 20 each. There was no significant difference between groups with regards to the root length $(p>0.05)$. To facilitate the manipulation of samples, the roots were mounted vertically in blocks made of a silicone impression material (President Jet; Coltène AG, Cuyahoga Falls, OH, USA) up to the cervical margin.

A pilot experiment was performed to determine the optimum consistency of the $\mathrm{Ca}(\mathrm{OH})_{2}$ paste for the study. Powder of L \& C paste (Dentisply, Petrópolis, RJ, Brazil) $(2 \mathrm{~g})$ mixed with glycerin (Hemafarma Comercio e Indústria Farmacêutica, São Gonçalo, RJ, Brazil) (2 $\mathrm{ml}$ ) was found to have the best consistency. The time of manipulation was 60 seconds. The same mixture was used for all groups and the same operator performed all techniques.

-Manual group (MAN)

A size $50 \mathrm{~K}$-file carrying $\mathrm{Ca}(\mathrm{OH})_{2}$ paste was inserted into the canals up to the apex and removed with counterclockwise movements. This procedure was repeated thrice for each tooth. Thereafter, a cotton pellet was applied gently onto the canal orifice.

-Lentulo group (LEN)

A Lentulo spiral (No. 4, Maillefer Instruments SA, Ballaigues, Switzerland) carrying $\mathrm{Ca}(\mathrm{OH})_{2}$ paste was inserted into the canals up to $2 \mathrm{~mm}$ from the root apex. The LEN was powered by a motor (VDW, Munich, Germany), in a clockwise movement at $1000 \mathrm{rpm}$. Slight pumping motion was applied. This procedure was repeated thrice for each tooth. Thereafter, a cotton pellet was applied gently onto the canal orifice.

-EndoActivator group (EA)

A size $50 \mathrm{~K}$-file carrying $\mathrm{Ca}(\mathrm{OH})_{2}$ paste was inserted into the canals up to the apex and removed with counterclockwise movements followed by application of the EndoActivator (Dentsply Tulsa Dental Specialties, Johnson City, TN, USA) (6) with a blue tip size \#35/0.04 positioned at $2 \mathrm{~mm}$ from the WL. The EndoActivator was activated at $6.000 \mathrm{cpm}$ for 20 seconds. This procedure was repeated thrice for each tooth. Thereafter, a cotton pellet was applied gently onto the canal orifice.

-Radiographic filling analysis

The roots were radiographed at buccolingual and mesiodistal directions, using occlusal radiographic films (Insight - Kodak Comp, Rochester, NY, USA) with an Xray unit (Raios-X Timex $70 \mathrm{E}$, GNATUS, $70 \mathrm{KVp}, 7.0$ $\mathrm{mA}$, Ribeirão Preto, SP, Brazil). The film-focus distance was set at $15 \mathrm{~cm}$, and the time of exposure was adjusted 
at $0.4 \mathrm{~s}$. Radiographs were manually processed using the same conditions of time and temperature for the three groups. The radiographs were then digitized using a digital camera (Canon G 9, Canon Inc., Lake Success, NY, USA). The quality of the fillings was evaluated, independently, by two qualified examiners (experienced endodontists), blinded to the techniques used in the experiment. The radiographic images were analysed on the computer screen in a darkened room. Both directions were evaluated for two parameters including the amount of voids and the apical limit of the root canal filling.

For the first analysis, the following scores were used: 1, no voids; 2 , presence of voids in less than $25 \%(<1 / 4$ th $)$ of the root canal area; 3 , presence of voids in $25 \%$ to $50 \%(1 / 4$ th to $1 / 2)$ of the area; 4 , voids in more than $50 \%$ $(>1 / 2)$ of area.

The second analysis was based on the apical limit of filling on the two radiographic views. The following scores were used: 1 , filling at the apex; 2 , filling short 1 to 2 $\mathrm{mm}$ from the apex; 3 , filling short more than $2 \mathrm{~mm}$ from the apex.

The concordance among the examiners was confirmed (kappa values $=0.55$ and 0.75 , respectively, for detectable voids and apical limit analyses). The worst score was used in cases of disagreement.

-Statistical analysis

Statistical analysis was performed to compare the means obtained by the two examiners. The scores for area of void based on the three filling techniques as well as the teeth length were compared between groups using the Kruskal-Wallis test. The Mann-Whitney test with the Bonferroni's correction was performed. All statistical tests were performed using the Statistical Package for the Social Sciences (SPSS) software, version 19.0 (IBM, São Paulo, SP, Brazil). A probability level of .05 was used as criterion for statistical significance.

\section{Results}

-Detectable voids

The amount of voids between the tested techniques showed statistical significant difference $(p<0.01)$. In general, EA group showed higher amount of voids, followed by MAN and LEN groups, in order (Table 1). Score (\#1) was not observed in any root. The occurrence of voids was evenly distributed along the canals.

-Apical limit

There was no statistical difference between the tested techniques with respect to the apical limit $(p>0.05)$. In general, the root canal filling in LEN and MAN groups was nearest to the apex, as compared to EA group (Table 2, Fig. 1)

\section{Discussion}

Calcium hydroxide paste is the most common intracanal medicament used in endodontics. The biological properties of $\mathrm{Ca}(\mathrm{OH})_{2}$, in particular the antimicrobial action and the repair stimulation by deposition of mineralized tissue are suitable for this application $(12,13)$. To maximize the benefit of their properties, $\mathrm{Ca}(\mathrm{OH})$, pastes must be in direct contact with the root canal walls and fill the total extension of the main canal space (4).

If the root canal is not well instrumented and irrigated, the medication will not be effective. Therefore, the root canal must be enlarged up to a diameter compatible with

Table 1: Number of canals per group and the quality of $\mathrm{CaOH}_{2}$ filling regarding the amount of voids (score)

\begin{tabular}{|c|c|c|c|c|}
\hline Groups & $\mathbf{1}$ (no voids) & $\mathbf{2}(<\mathbf{2 5} \%)$ & $\mathbf{3}(\mathbf{2 5 \%}$ to $\mathbf{5 0} \%)$ & $\mathbf{4}(\mathbf{5 0} \%)$ \\
\hline MAN $^{\mathrm{a}}$ & 0 & 6 & 12 & 2 \\
\hline LEN $^{\mathrm{a}}$ & 0 & 9 & 11 & 0 \\
\hline EA $^{\mathrm{b}}$ & 0 & 1 & 9 & 10 \\
\hline
\end{tabular}

Different superscript letters indicate significant differences.

Table 2: Number of canals per group and the quality of $\mathrm{CaOH} 2$ fill regarding the apical limit (score).

\begin{tabular}{|c|c|c|c|}
\hline Groups & $\mathbf{1}$ & $\mathbf{2}$ & $\mathbf{3}$ \\
\hline MAN $^{\mathrm{a}}$ & 3 & 12 & 5 \\
\hline LEN $^{\mathrm{a}}$ & 0 & 16 & 4 \\
\hline EA $^{\mathrm{a}}$ & 3 & 10 & 7 \\
\hline
\end{tabular}

its anatomical condition $(4,14,15)$. Regardless of the application mode, filling with medication is not effective in slightly enlarged canals (8). In the present study, the apical preparation was standardized at $0.50 \mathrm{~mm}$ for all root canals to guarantee sufficient enlargement for the filling with medication. Additionally, dentin root canals were used in this study only as a tube for medication filling.

In the present study, lentulo spiral was activated at 1000 rpm with an electric motor, as previously reported (16), 


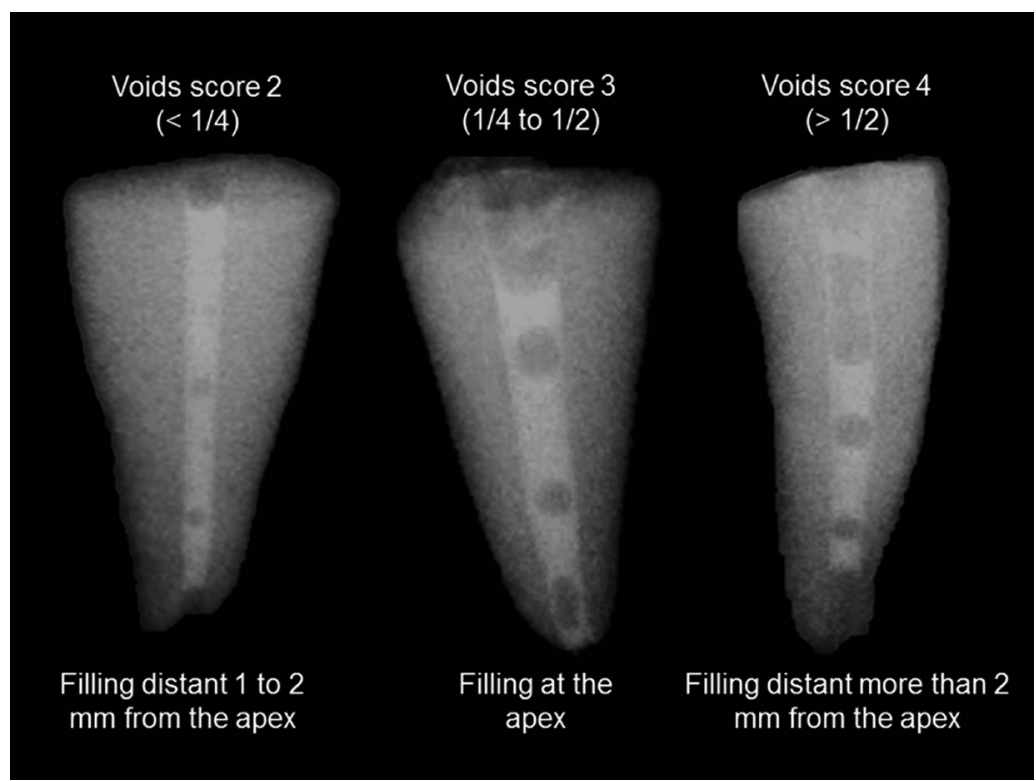

Fig. 1: Radiographic filling analysis considering detectable voids and apical limit following the adopted criteria. The better score for detectable voids (\#1) was not observed in any root. From the left to the right are specimens from groups: LEN, the technique using rotary Lentulo spiral; MAN, conventional technique using a hand instrument; and EA, a mixed technique combining conventional hand file with sonic activation with the EndoActivator device.

to avoid any bias related to the speed, which is variable when using compressed air motors. The application of $\mathrm{Ca}(\mathrm{OH})_{2}$ paste with lentulo produced a more homogenous filling followed by manual technique, without statistical difference between them. Moreover, a previous study (17) reported that counterclockwise rotation of $\mathrm{K}$-files did not result in acceptable fillings in root canals enlarged with a $\# 25$ file. In the current study, regardless of the application technique, none of the roots showed a better score. Inadequate quality of filling is a special clinical concern in most cases, independent of the insertion technique (score 3 in 53\% of cases).

Many studies showed that lentulo spiral was effective in producing homogenous fillings with $\mathrm{Ca}(\mathrm{OH})_{2}(16-20)$, but the effectiveness of EndoActivator for this purpose has not been addressed in previous study. $\mathrm{Ca}(\mathrm{OH})_{2}$ pastes are also available in injectable dispensing forms using special syringes and needles, but the hydraulic pressure required to fill the canals increases the possibility of paste extrusion to the periradicular tissues (21).

The tested techniques were similar in terms of the apical limit, without statistical difference between them. In most cases, the apical limit ranged from 1 and $2 \mathrm{~mm}$ from the apex (score 2 in $63 \%$ of cases), indicating that none of the tested techniques fully satisfied this requirement. These results corroborate those from a previous study that compared four techniques using Lentulo or Navitip with and without a $\mathrm{Ca}(\mathrm{OH})_{2}$ point inserted into the root canal. The apical portion of root canals was unfilled in all techniques (22). In contrast, an earlier study (17) found that Lentulo spiral was significantly more effective in carrying the paste to WL than counterclockwise rotation of K-files. However, the results of the previous study require careful interpretation, considering the limited number of tested samples.

The technique with EndoActivator was less effective than Lentulo and manual techniques, contradicting the first hypothesis. This application mode was suggested by Ruddle (11), but had not been previously tested. Based on the results of the present study, the use of EndoActivator is contraindicated for this purpose. Sonic agitation seems to dislodge the medication and does not favour the filling.

The present study has some limitations including the use of teeth with non-complicated root canal anatomy, the two-dimensional analysis, and the in vitro experimental design. For these reasons, the results are not directly applicable to the clinical field.

\section{Conclusions}

Considering the limits of this in-vitro study and the fact that the root canals employed presented non-complicated anatomy, is concluded that well performed manual insertion of $\mathrm{Ca}(\mathrm{OH})_{2}$ paste produced similar quality of filling in comparison with Lentulo technique, and both were better than the technique with EndoActivator. However, none root canal was completely filled with the paste and the apical limit was achieved in a few cases, independently of the technique. These statements encouraging the development of more effective $\mathrm{Ca}(\mathrm{OH})_{2}$ filling techniques. 


\section{References}

1. Siqueira JF Jr, Rocas IN. Optimising single-visit disinfection with supplementary approaches: a quest for predictability. Aust Endod J. 2011;37:92-8

2. Vera J, Siqueira JF, Jr., Ricucci D, Loghin S, Fernandez N, Flores B, et al. One- versus two-visit endodontic treatment of teeth with apical periodontitis: a histobacteriologic study. J Endod. 2012;38:1040-52.

3. Ricucci D, Russo J, Rutberg M, Burleson JA, Spangberg LS. A prospective cohort study of endodontic treatments of 1,369 root canals: results after 5 years. Oral Surg Oral Med Oral Pathol Oral Radiol Endod. 2011;112:825-42.

4. Mohammadi Z, Dummer PM. Properties and applications of calcium hydroxide in endodontics and dental traumatology. Int Endod J. 2011:44:697-730.

5. Estrela C, Mamede Neto I, Lopes HP, Estrela CR, Pecora JD. Root canal filling with calcium hydroxide using different techniques. Braz Dent J. 2002;13:53-6.

6. Deveaux E, Dufour D, Boniface B. Five methods of calcium hydroxide intracanal placement: an in vitro evaluation. Oral Surg Oral Med Oral Pathol Oral Radiol Endod. 2000;89:349-55.

7. Oztan MD, Akman A, Dalat D. Intracanal placement of calcium hydroxide: a comparison of two different mixtures and carriers. Oral Surg Oral Med Oral Pathol Oral Radiol Endod. 2002;94:93-7.

8. Simcock RM, Hicks ML. Delivery of calcium hydroxide: comparison of four filling techniques. J Endod. 2006;32:680-2.

9. Blank-Goncalves LM, Nabeshima CK, Martins GH, Machado ME. Qualitative analysis of the removal of the smear layer in the apical third of curved roots: conventional irrigation versus activation systems. J Endod. 2011;37:1268-71

10. Nikhil V, Singh R. Confocal laser scanning microscopic investigation of ultrasonic, sonic, and rotary sealer placement techniques. J Conserv Dent. 2013;16:294-9.

11. Ruddle CJ. Endodontic advancements: game-changing technologies. Dent Today. 2009;28:82, 4.

12. Kitikuson P, Srisuwan T. Attachment Ability of Human Apical Papilla Cells to Root Dentin Surfaces Treated with Either 3Mix or Calcium Hydroxide. J Endod. 2016;42:89-94.

13. Silveira AM, Lopes HP, Siqueira JF, Jr., Macedo SB, Consolaro A. Periradicular repair after two-visit endodontic treatment using two different intracanal medications compared to single-visit endodontic treatment. Braz Dent J. 2007;18:299-304.

14. Holland R, Otoboni Filho JA, de Souza V, Nery MJ, Bernabe PF, Dezan E, Jr. A comparison of one versus two appointment endodontic therapy in dogs' teeth with apical periodontitis. J Endod. 2003;29:121-4.

15. Siqueira JF Jr, Lopes HP. Mechanisms of antimicrobial activity of calcium hydroxide: a critical review. Int Endod J. 1999;32:361-9.

16. Peters CI, Koka RS, Highsmith S, Peters OA. Calcium hydroxide dressings using different preparation and application modes: density and dissolution by simulated tissue pressure. Int Endod J. 2005;38:88995.

17. Sigurdsson A, Stancill R, Madison S. Intracanal placement of $\mathrm{Ca}(\mathrm{OH}) 2$ : a comparison of techniques. J Endod. 1992;18:367-70.

18. Dumsha TC, Gutmann JL. Clinical techniques for the placement of calcium hydroxide. Compend Contin Educ Dent 1985;6:482-3,6,8-9.

19. Staehle HJ, Thoma C, Muller HP. Comparative in vitro investigation of different methods for temporary root canal filling with aqueous suspensions of calcium hydroxide. Endod Dent Traumatol. 1997; 13:106-12.

20. Torres CP, Apicella MJ, Yancich PP, Parker MH. Intracanal placement of calcium hydroxide: a comparison of techniques, revisited. J Endod. 2004:30:225-7.

21. Tan JM, Parolia A, Pau AK. Intracanal placement of calcium hydroxide: a comparison of specially designed paste carrier technique with other techniques. BMC Oral Health. 2013;13:52.

22. Rahde Nde M, Figueiredo JA, Oliveira EP. Influence of calcium hydroxide points on the quality of intracanal dressing filling. J Appl Oral Sci. 2006;14:219-23.
Acknowledgments

This study was supported by grants from Fundação de Amparo à Pesquisa do Estado do Rio de Janeiro (FAPERJ), a Brazilian Governmental Institution.

\section{Conflict of Interest}

The authors deny any conflicts of interest. 